Lastly, I would call attention to a symptom of fractured skull which this case presented in a marked manner, and which I have found of the greatest service in determining the presence of a fracture of the skull when even a local thickening or bogginess of the subcutaneous tissues about the seat of fracture was absent. I refer to the loss of ring on percussion which such a crack in the skull produces. I have no doubt that this simple but most important symptom must be familiar to many surgeons, though, curiously, I have known no one else use it, nor have I seen it mentioned in any work on fractures. The absence of ring, any local bogginess of the soft parts being allowed for, is a very certain indication of a fracture, and by carefully tapping with the finger or pleximeter, the extent and position of the fracture can generally be determined with accuracy.

St. Thomas's-str'eet, S.E.

\section{DILATED URACHUS TREATED BY INCISION AND DRAINAGE. ${ }^{1}$}

\section{BY REGINALD PRATT, M.D.LOND., AND \\ C. J. BOND, F.R.C.S.ENG.}

W. J. P-, a gentleman aged fifty-four years, consulted Dr. Pratt on June 8th, 1889, complaining of pain and distension in the bowels and increasing general weakness. He was quite well until the previous November, when he was taken ill with pains in the lower part of the bowels; he kept in bed for three weeks and in the house for four months. He could not account for the onset of the disease in any way; there had been no blow, lifting of heavy weights, or straining of any kind. His occupation was that of a storekeeper and clerk near New York, where he had lived many years. He was married and had three children ; the eldest died at three years of age from pneumonia; another was drowned at birth ; the other died at eleven months from convulsions. He had gonorrhoea when twenty-one years of age, but never had any symptom of syphilis. He led a very intemperate life until seven or eight years ago ; since then he had been a moderate drinker. A grandmother and an aunt were supposed to have died from cancer of the bowels; the patient's father, a grandfather, three brothers, and one sister had died from consumption. The abdomen was found to be much distended in the lower half in front, the distended area was dull on percussion, and extended as high as three fingers' breadth above the umbilicus and down as far as the pubes, laterally on each side as far as vertical lines drawn through the anterior superior iliac spines, projecting rather more to the left than to the right side; the flanks were perfectly resonant, the tumour fluctuated. The circumference of the abdomen between the umbilicus and pubes measured $41 \frac{1}{2}$ in.; nine months ago it was 34 in. He weighed $182 \mathrm{lb}$., his weight for the last twenty years having been $175 \mathrm{lb}$. Height, $6 \mathrm{ft}$. $1 \mathrm{in}$. The lungs appeared to be normal. The cardiac apex beat was in the lett nipple line; the first sound at apex was weak, no murmur. Pulse 84, regular, small, and compressible. Liver dulness extended two fingers' breadth below the margin of the thorax, the upper limit was normal. No trouble with micturition or defecation, except slight constipation. Urine acid, no deposit, pale sherry colour, sp. gr. 1020, no albumen, no sugar, urea 1.45 per cent., quantity about normal. A catheter was passed immediately after micturition, only a few drops of urine being withdrawn. Examined per rectum the prostate was not enlarged, but there was a fulness filling up the left side of the pelvis. On June 15th, 1889, the tumour was aspirated, and about one drachm of a gummy, semi-transparent fluid withdrawn which blocked the tube; this contained only a trace of albumen, but a large quantity of mucin, as shown by the precipitate it gave with acetic acid, which was soluble in nitric acid; examined microscopically, it showed many leucocytes. The temperature was ordered to be taken. On June 30 th, the temperature was about $99^{\circ}$ in the morning, at or above $100^{\circ}$ in the evening. There had also been profuse night sweats. Mr.

I A paper read before the Leicester Medical Society.
Bond saw the patient with Dr. Pratt on June 30th, and it was decided to perform abdominal section.

On July 9th, 1889, Mr. Bond made a four-inch median incision midway between the umbilicus and the pubes. After dividing the linea alba a very thick membrane was reached resembling the peritoneum much thickened by tubercular peritonitis. This proved to be the outer wall of the cyst; it was divided, and a very large quantity, of which over a gallon was measured, of a ropy, gummy, semi-solid, laminated substance, having the appearance and consistence of semi-decolourised fibrin, was partly squeezed and partly drawn out in stringy layers. A considerable quantity was left in the cavity, as any attempt to sponge it off the inner surface of the cyst wall left a red raw surface which bled freely, the blood being remarkably fluid. On exploring the cavity with the hand and arm, it was found to extend upwards to and beneath the liver, and downwards into the pelvis; the intestines could be made out behind and at the sides of the cyst, though shut off and separated from it. 'The cavity of the peritoneum was not opened. A Keith's glass drainage-tube was placed in the wound reaching to the floor of the pelvis, and the rest of the incision closed. Strict antiseptics were used and a sublimate wool dressing applied over the tube and the wound. The fluid was kindly examined by Messrs. Richardson and Co., who reported that it contained not more than traces of albumen, that the whole was practically mucus and fibrin with a large predominance of the former; microscopic examination showed abundance of mucus-corpuscles with which were mixed some blood-corpuscles. The after progress of the case was very satisfactory; the wound remained aseptic, and large quantities of the mucoid material were aspirated or squeezed out through the tube, which was removed, cleaned, and replaced twice a day. The cyst walls shrank very considerably, the evening temperature did not reach the normal until six weeks after the operation, and the night sweats continued for several weeks also. In December, 1889, on his departure for America, he seemed to be in good health, could walk nine miles at a stretch, and his appetite was excellent; there still remained an irregular shaped cavity with thickened walls, capable of holding half a pint of fluid. Mucoid material was secreted daily ; the discharge of this, however, which was quite sweet, did not seem in any way to depress the health. In a letter dated Feb. 27 th, 1890 , the patient says the wound is still kept open by a glass tube, it discharges clear watery fluid with very little of the jelly-like material, the discharge is not at all offensive, and the general health is excellent. He works thirteen hours a day; his weight is $175 \mathrm{lb}$, and he measures 36 in. round the abdomen, between the umbilicus and pubes. He has strict orders not to allow the wound to close.

The diagnosis rested between hydatid tumour, encysted peritonitis (tubercular or cancerous), a tumour which had undergone mucoid degeneration, and an enormously dilated urachus. The detection of mucus in the contents of the cyst excluded hydatid tumour as well as encysted peritonitis, for, as Mr. Shattock, who kindly examined some of the fluid, writes, it is impossible for a mucous fluid to be secreted by a serous membrane. The presence of a my xomatous tumour was negatived at the operation. The case must therefore be one of immensely dilated persistent urachus. Leicester.

\section{A CASE OF}

\section{SUPRA-PUBIC LITHOTOMY WITH SUTURE} OF THE BLADDER.

BY A. R. ANDERSON, F.R.C.S., SURGEON TO THE GENERAI HOSPITAL, NOTTINGHAMr.

F. W-, aged ten, was admitted into hospital with supposed stone in the bladder. On being questioned, he gave the usual history of such a case, the symptoms having certainly been present for a year--perhaps for longer,-but his suffering was slight and he did not complain loudly. The urine was clear, acid, with a slight cloud of mucus ; no albumen and no deposit. A stone was easily felt in the bladder on passing a sound. On Nov. 5th, 1889, I performed supra-pubic lithotomy. A rectal bag was used and distended with five ounces of water. A catheter was then passed into 